\title{
SEVERE HYPERNATREMIC DEHYDRATION IN A BREASTFED INFANT
}

\author{
Faton KRASNIQI ${ }^{1}$, Lindita KRYEZIU ${ }^{1}$, Haki JASHARI ${ }^{1,2}$
}

${ }^{1}$ Neonatology Clinic, University Clinical Center of Kosovo, Prishtina, Kosovo, ${ }^{2}$ Department of Public Health and Clinical Medicine, Umeå University, Sweden

Correspondence: dr_faton_krasniqi@hotmail.com Tel.: + 37744239750

Received: January 25, 2016

Accepted: June 13, 2016

Key words: Hypernatremic dehydration Newborn - Breastfeeding.
Objective - To report a rare case of hypernatremic dehydration in an exclusively breastfed infant. Case report - We present a term newborn, 14-day-old boy, exclusively breastfed, who was lethargic and severely dehydrated upon admission (35\% birth weight loss). The newborn was found to have severe hypernatremic dehydration $\left(\mathrm{Na}^{+}\right.$ $197 \mathrm{mmol} / \mathrm{l}$ ), acute renal insufficiency (Creatinine $273 \mu \mathrm{mol} / \mathrm{l}$ ) and metabolic acidosis. Also, the blood culture result was positive. Intravenous rehydration and antibiotic therapy were started. After 22 days of hospitalization, the infant was discharged home in a good general condition. Now the child is 13 months old, he is healthy and no neurologic sequelae are noticed. Conclusion - Hypernatremic dehydration in newborns is a rare complication, which is dangerous, but also preventable. Prevention consists in educating mothers about successful breastfeeding techniques, and also early newborn reassessment after discharge from the hospital is mandatory.

\section{Introduction}

Breast milk is the best nutritional choice for the newborn. Breastfeeding is a natural process, yet it is new for both the mother and baby, and many need help to prevent failure and the consequent complications. Hypernatremic dehydration might be a complication of such a failure, which, if not treated promptly, may lead to acute renal failure and the need for peritoneal dialysis (1).

Hypernatremic dehydration in newborns occurs more often than hyponatremic dehydration, but more rarely compared to isonatremic dehydration. It manifests with very poor clinical features and has a worse outcome than other types of dehydration. In recent years a higher incidence of hypernatremic dehydration in neonates has been reported. Inadequate breastfeeding techniques might be responsible, hence it has been noticed more often in primiparous mothers (2-4).
This report describes an exclusively breast-fed infant with severe hypernatremic dehydration.

\section{Case report}

A 14-day-old male infant was admitted to the ICU of the Neonatology Clinic due to breastfeeding refusal, irritability and decreased urine output in previous days. $\mathrm{He}$ was born at term ( 40 gestational weeks) to a 24 year old, healthy, primiparous mother, by vaginal delivery, at a regional hospital. His birth weight was $3700 \mathrm{~g}$, Apgar score 8/9 and no complications were noticed. Likewise, the infant was discharged from hospital in the second day following birth. The mother denies having had mastitis or any drug use, and also denies the presence of vomiting or diarrhea in the infant. The infant was exclusively breast fed 8-10 times a day. During this pe- 
riod, the mother was not aware of inadequate breastfeeding and the risk posed to her malnourished infant. Furthermore, in the following days the infant was apathetic, sleepy, suckling poorly and had a poor urinary output. At that point, the mother sought medical help at the regional hospital, which immediately transferred the infant to our clinic.

Upon admission, the infant was afebrile $\left(36.5^{\circ} \mathrm{C}\right)$, eupneic, had no convulsions, cyanosis or jaundice. His heart rate was 160/ min and blood pressure was not measurable. His respiratory rate was $40 / \mathrm{min}$ and oxygen saturation measured by pulse oximetry was $96 \%$. Physical examination revealed a sick infant, lethargic and severely dehydrated. Body weight was 2400 g, i.e., a $35 \%$ below the body weight at birth. A sunken anterior fontanelle, dry mucous membranes and a 4 second capillary refill time were found (Fig. 1).
Neurological examination revealed a lethargic and sleepy infant, while primitive reflexes were preserved. Cranial ultrasound results were normal. Abdominal ultrasound showed slightly hyper-echogenic kidneys. An intravenous line was started, and blood was drawn for culture, electrolytes, complete blood count, random glucose, urea, creatinine and liver function tests. Laboratory findings were as follows: $\mathrm{pH} 7.29, \mathrm{pCO}_{2} 40$ $\mathrm{mmHg}, \mathrm{Na}^{+} 197 \mathrm{mmol} / \mathrm{l}, \mathrm{K}^{+} 5.2 \mathrm{mmol} / \mathrm{l}$, $\mathrm{HCO}_{3}^{-} 19.2 \mathrm{mmol} / \mathrm{l}$, Urea $95.6 \mathrm{mmol} / \mathrm{l}(576$ $\mathrm{mg} / \mathrm{dl})$, Creatinine $273 \mu \mathrm{mol} / \mathrm{l}(3.08 \mathrm{mg} / \mathrm{dl})$, AST 112 U/l, ALT $61 \mathrm{U} / 1$, blood glucose 3.9 $\mathrm{mmol} / \mathrm{l}, \mathrm{WBC} 8500 / \mathrm{mm}^{3}$, Hgb $19.1 \mathrm{~g} / \mathrm{dl}$, HCT $60.4 \%$ and PLT $38.000 / \mathrm{mm}^{3}$.

A bolus of $10 \mathrm{ml} / \mathrm{kg}$ normal saline was administered and repeated twice until hemodynamic stability was achieved. Shortly after that, the administration of 5\% dextrose

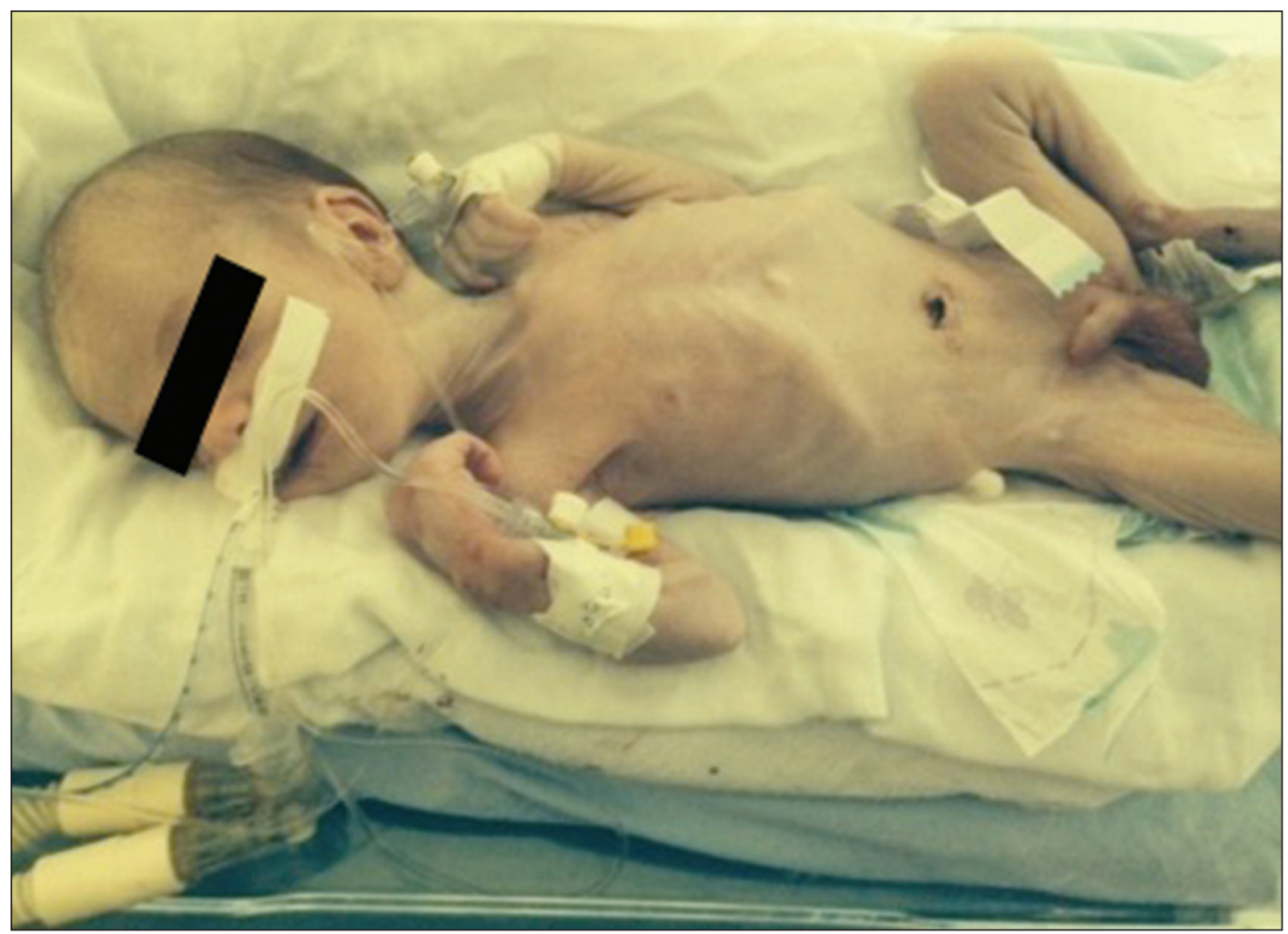

Fig. 1 Infant shortly after admission. 
solution with $0.45 \%$ saline was started for the next 96 hours $(7.61 \mathrm{ml} / \mathrm{kg} / \mathrm{h})$. Intravenous ceftriaxone was started together with inotropic support (dopamine). Fresh plasma was also administered because of the severe hypovolemia and septic appearance of the infant. Urine output on the first day of hospitalization was $0.8 \mathrm{ml} / \mathrm{kg} / \mathrm{h}$. On the second day of hospitalization, the infant manifested respiratory failure (apnea, gasping, $\mathrm{O}_{2}$ saturation $<85 \%$ ), hence intubation and mechanical ventilation was required for the next five days. Sepsis was postulated as a possible cause, since the chest X-ray showed insignificant changes. On the third day, the blood culture came back positive for Enterobacter. Antibiotic therapy was changed based on the antibiotic sensitivity tests (meropenem and ampicillin + sulbactam). Urine was latex agglutination negative, culture sterile and cerebrospinal fluid sterile. Rehydration continued until correction of the sodium level was achieved, while taking care not to overcorrect the sodium concentration; i.e. not faster than
10-12 mEq/24 h (5). Enteral feeding started on the fourth day, increasing day by day to fully enteral on the $10^{\text {th }}$ day. Urea and Creatinine normalized on the $10^{\text {th }}$ day of hospitalization $(1.92 \mathrm{mmol} / \mathrm{l}$ and $50.2 \mu \mathrm{mol} / \mathrm{l}$, respectively) (Table 1 ).

On the $22^{\text {nd }}$ hospital day the infant was discharged from the clinic. The mother received instructions on adequate breast-feeding, as well as supplementing with formula. The baby's weight on discharge was $3755 \mathrm{~g}$. Now the child is 13 months old, he is healthy and no neurologic sequelae are noticed, however regular consultations with a Pediatric Neurologist are advised.

\section{Discussion}

Breastfeeding is undoubtedly the best, safest and healthiest way to feed an infant. Hypernatremic dehydration was thought to be unusual in exclusively breastfed infants. However, reports on this issue have been increasingly frequent over the last two decades.

Table 1 Laboratory results of the patient by days

\begin{tabular}{|c|c|c|c|c|c|c|c|c|c|c|}
\hline \multirow{2}{*}{ Laboratory findings } & \multicolumn{10}{|c|}{ Days } \\
\hline & $1^{\text {st }}$ & $2^{\text {nd }}$ & $3^{\text {th }}$ & $4^{\text {th }}$ & $5^{\text {th }}$ & $6^{\text {th }}$ & $7^{\text {th }}$ & $8^{\text {th }}$ & $9^{\text {th }}$ & $10^{\text {th }}$ \\
\hline $\mathrm{pH}$ & 7.29 & 7.49 & 7.6 & 7.46 & 7.44 & 7.48 & 7.36 & 7.38 & 7.36 & 7.41 \\
\hline $\mathrm{pCO}_{2}(\mathrm{mmHg})$ & 40 & 26 & 18 & 31 & 30 & 32 & 39 & 51 & 42 & 46 \\
\hline $\mathrm{Na}^{+}(\mathrm{mmol} / \mathrm{l})$ & 197 & 191 & 180 & 167 & 152 & 148 & 138 & 135 & 139 & 138 \\
\hline $\mathrm{K}^{+}(\mathrm{mmol} / \mathrm{l})$ & 5.2 & 4.0 & 4.6 & 5.3 & 4.6 & 4.2 & 4.3 & 4.1 & 5.1 & 4.4 \\
\hline $\mathrm{Ca}^{++}(\mathrm{mmol} / \mathrm{l})$ & 1.36 & 1.35 & 1.43 & 131 & 1.23 & 1.21 & 1.16 & 1.17 & 1.21 & 1.1 \\
\hline $\mathrm{HCO}_{3^{-}}(\mathrm{mmol} / \mathrm{l})$ & 19.2 & 19.8 & 17.7 & 22.0 & 24.1 & 23.3 & 21.2 & 30.2 & 26.3 & 28.2 \\
\hline Urea $(\mathrm{mmol} / \mathrm{l})$ & 95.6 & 90.8 & 66.2 & 57.7 & - & - & - & 18.2 & - & 1.9 \\
\hline Creatinine $(\mu \mathrm{mol} / \mathrm{l})$ & 273 & 274 & 345 & 277 & - & - & - & 123 & - & 50.2 \\
\hline $\operatorname{AST}(\mathrm{U} / \mathrm{l})$ & 112 & - & - & - & - & - & - & 22 & - & 54 \\
\hline $\operatorname{ALT}(\mathrm{U} / \mathrm{l})$ & 61 & - & - & - & - & - & - & 62 & - & 32 \\
\hline WBC $\left(\mathrm{mm}^{3} \times 10^{3}\right)$ & 8.5 & - & 12.7 & - & - & - & - & 5.3 & - & 8.8 \\
\hline $\operatorname{RBC}\left(\mathrm{mm}^{3} \times 10^{6}\right)$ & 5.91 & - & 5.9 & - & - & - & - & 5.23 & - & 4.44 \\
\hline HCT (\%) & 60.4 & - & 59.8 & - & - & - & - & 48.4 & - & 41 \\
\hline PLT $\left(\mathrm{mm}^{3} \times 10^{3}\right)$ & 38 & - & 23 & - & - & - & - & 60 & - & 221 \\
\hline CRP (mg/l) & 68.1 & - & 25.2 & - & - & 17.6 & - & 3.2 & - & - \\
\hline
\end{tabular}


Manganaro et al. found that $7.7 \%$ of healthy newborns lost more than $10 \%$ of their weight in the first week of life, $36 \%$ of which had hypernatremic dehydration (6). Oddie et al. showed that weight loss at presentation was significantly associated with age and serum sodium at presentation (4). However, severe life threating hypernatremic dehydration is usually reported anecdotally in case studies $(7,8)$, often with fatal outcome $(9,10)$.

Hypernatremic dehydration in exclusively breastfed infants usually occurs between the first and the third week of life, and can be difficult to recognize clinically (11). Most infants are reported to present with jaundice or are lethargic, septic and irritable. Since infants with hypernatremic dehydration have better preserved extracellular volume (12), clinical signs of dehydration are usually noticed only in severely dehydrated patients. Mothers are usually primiparous women and very motivated to breastfeed. They usually describe their infants as sleepy, lazy and not willing to breastfeed, hence in the end the baby's nutritional needs are not adequately met (13). Likewise, the mothers are prone to delay seeking medical help.

It is very important to assure successful breastfeeding before discharge. Breast conditions associated with breast-feeding difficulties (flat or inverted or large nipples and huge, engorged breasts), primiparity, pink diaper, delay of initiation of first breast giving, birth by cesarean section, extra heater usage, and mean uric acid concentration in neonates with pink diaper, were all significantly related to hypernatremic dehydration (14). Hence, delayed discharge and additional help for these cases must be considered, until successful breastfeeding is established. Moreover, the mother's persistence on exclusively breastfeeding her baby might expose the infant to such a risk, thus consulting a pediatrician early after discharge is important.

Neurologic sequelae are described among children with hypernatremia (15). Moreover, a recent prospective study revealed abnormal neurological development in more than half the infants admitted due to breastfeedingassociated hypernatremia (16). Thus, careful and long follow up for eventual neurologic sequelae should be conducted.

It is important to be open-minded when dealing with severely sick infants. A positive blood culture shows that we should not attribute all symptoms to hypernatremic dehydration. Thus, a full clinical work-up is needed in these infants.

\section{Conclusion}

Hypernatremic dehydration in exclusively breastfed infants is preventable. Neonates with the aforementioned risk factors should be discharged only after successful breastfeeding has been established. Also, close follow-up of infants within the first week after discharge to check weight gain will help in preventing and early identification of hypernatremic dehydration.

Authors' contributions: Conception and design: FK and HJ; Acquisition, analysis and interpretation of data: FK, LK, and HJ; Drafting the article: FK; Revising the article critically for intellectual content: $\mathrm{HJ}$ and LK; Approved final version of the manuscript: FK, L $\mathrm{K}$ and $\mathrm{HJ}$.

Conflict of interest: The authors declare that they have no conflict of interest.

\section{References}

1. Ali US, Sengupta K, Andankar P, Saraf S, Chawla A, Deshpande S. Reversible renal medullary hyperechogenicity in neonatal hypernatremic dehydration. Pediatr Nephrol. 2004;19(9):1050-2.

2. Cooper WO, Atherton HD, Kahana M, Kotagal UR. Increased incidence of severe breastfeeding malnutrition and hypernatremia in a metropolitan area. Pediatrics. 1995;96(5 Pt 1):957-60.

3. Kaplan JA, Siegler RW, Schmunk GA. Fatal hypernatremic dehydration in exclusively breast-fed newborn infants due to maternal lactation failure. Am J Forensic Med Pathol. 1998;19(1):19-22. 
4. Oddie SJ, Craven V, Deakin K, Westman J, Scally A. Severe neonatal hypernatraemia: a population based study. Arch Dis Child Fetal Neonatal Ed. 2013;98(5):F384-7.

5. Schwaderer AL, Schwartz GJ. Treating hypernatremic dehydration. Pediatr Rev. 2005;26(4):14850.

6. Manganaro R, Mamì C, Marrone T, Marseglia L, Gemelli M. Incidence of dehydration and hypernatremia in exclusively breast-fed infants. J Pediatr. 2001;139(5):673-5.

7. Zaki SA, Mondkar J, Shanbag P, Verma R. Hypernatremic dehydration due to lactation failure in an exclusively breastfed neonate. Saudi J Kidney Dis Transpl. 2012;23(1):125-8.

8. Smith RG. Severe hypernatremic dehydration in a newborn infant. Paediatr Child Health. 1998;3(6):413-5.

9. van Amerongen RH, Moretta AC, Gaeta TJ. Severe hypernatremic dehydration and death in a breastfed infant. Pediatr Emerg Care. 2001;17(3):17580 .

10. Jaramillo I, Lopez G, Hernandez H. Hypernatremic dehydration and death in an infant. Pediatr Emerg Care. 2003;19(1):62-3.
11. Moritz ML, Manole MD, Bogen DL, Ayus JC. Breastfeeding-associated hypernatremia: are we missing the diagnosis? Pediatrics. 2005;116(3):e343-7.

12. Moritz ML, Ayus JC. Disorders of water metabolism in children: hyponatremia and hypernatremia. Pediatr Rev. 2002;23(11):371-80.

13. van der Heide PA, Toet MC, van Diemen-Steenvoorde JA, Renardel de Lavalette PA, de Jonge GA. Hypertonic dehydration in "silent" malnutrition of breast-fed infants [Dutch]. Ned Tijdschr Geneeskd. 1998 2;142(18):993-5.

14. Caglar MK, Ozer I, Altugan FS. Risk factors for excess weight loss and hypernatremia in exclusively breast-fed infants. Braz J Med Biol Res. 2006;39(4):539-44.

15. Morris-Jones PH, Houston IB, Evans RC. Prognosis of the neurological complications of acute hypernatraemia. Lancet. 1967;2(7531):1385-9.

16. Ergenekon E, Unal S, Gücüyener K, Soysal SE, Koç E, Okumus N, et al. Hypernatremic dehydration in the newborn period and long-term follow up. Pediatr Int. 2007;49(1):19-23. 